\title{
LUT
}

University

\section{In defense of 'eco' in innovation ecosystem}

Ritala Paavo, Almpanopoulou Argyro

This is a Post-print version of a publication

published by Elsevier

in Technovation

DOI: 10.1016/j.technovation.2017.01.004

Copyright of the original publication: @) 2017 Elsevier Ltd.

Please cite the publication as follows:

Ritala, P., Almpanopoulou, A. (2017). In defense of 'eco' in innovation ecosystem. Technovation, vol. 60-61, pp. 39-42. DOI: 10.1016/j.technovation.2017.01.004

This is a parallel published version of an original publication.

This version can differ from the original published article. 


\section{IN DEFENSE OF ‘ECO’ IN INNOVATION ECOSYSTEM}

Abstract: Innovation ecosystem is an increasingly popular but all too often ambiguously utilized concept across academia, policy and business. In their recent well-argued critique of the concept, Oh et al. (2016) called it a "flawed analogy" that is potentially dangerous for its lack of rigor. This letter, we reflect on this critique and examine pathways to resolve some of the issues pointed out. We suggest that, at its best, the ecosystem analogy combines salient features from natural ecology to inform the design of system-level innovation management activities. This requires great deal of conceptual and empirical effort and rigor, and we outline a number of ideas for future research in this regard.

\section{Introduction: What should we do with an analogy that became too popular?}

Business and management research boasts a high variety of concepts, reflecting the process of on-going change in the broader society, business, and technologies. From time to time, new "buzz" concepts emerge, attracting a lot of researcher and practitioner attention, only to fade away as new trends steal the spotlight. Some of these concepts last longer, creating independent and impactful fields of inquiry; either way, only time can determine their longevity. Innovation ecosystems is one such concept. Reflecting the ever-increasing connectivity of innovation activities, it joins the long list of other terms describing the networked and systemic nature of innovation.

References to innovation ecosystems have appeared in policy and business discussions, and academics have followed suit with a surge of case studies, conceptualizations, and other approaches that seek to understand and explain the phenomenon. The problem is that there is no consensus on the term's definition, scope, boundaries, or theoretical roots. In a recent article in Technovation, Oh et al. (2016) elaborated a well-grounded critique of the concept of innovation ecosystem, suggesting that it is a flawed analogy and does not necessarily add much value to the existing innovation systems literature.

We agree wholeheartedly that the concept is used loosely and inconsistently, resulting in its ambiguous input to scholarly discourse. However, given the rapid expansion of interest in the concept, it seems worthwhile to pursue greater academic rigor and concept clarity in its use. Thus, this letter is a reflection to the critique posed by Oh and colleagues, aiming to assess the 
potential merits of innovation ecosystem as a self-standing concept, and to examine ways to move forward.

\section{Unpacking the terminology}

Based on Durst and Poutanen's (2013) review, Oh et al. (2016, p. 2) argue that the innovation ecosystem literature pays insufficient attention to the "dialog with multiple constituents". Drawing from this, we argue that the term ecosystem demands attention to both of its parts: eco and system. Coupled with a focus on innovation activities, this serves to define a point of departure for a rigorous investigation of innovation ecosystems.

The prefix eco in innovation ecosystems implies a specifically ecological aspect. As delineated by Moore (1993) in introducing the ecosystem concept to management studies, these ecological aspects relate to the interdependency among different actors, and to the co-evolution that binds them together over time. The term co-evolution refers to a two-way interaction between two entities that may induce change in some direction (Peltoniemi, 2006). In innovation ecosystems, which comprise numerous actors in different layers, an actor's decisions may cause a counter-response from other actors. This behavior is multiplied in complex interdependencies across the ecosystem. Thus, it is essential to understand and take account of the link between micro and macro behaviors, as well as the cooperative and competitive interactions among the ecosystem's various actors (Peltoniemi, 2006; Overholm, 2015), which in turn affect the balance and dynamics of the ecosystem (Valkokari, 2015).

From a systems science perspective, the term system refers to a specific set of components (actors, organizations, entities) that are interdependent but independent of other systems (e.g., von Bertalanffy, 1956). In fact, innovation ecosystem could be fundamentally portrayed as a specific application of a complex adaptive system (see e.g. Anderson, 1999; Cilliers, 2005). Such underlying systems foundation is also recognized in the ecosystem literature (e.g., Peltoniemi, 2006; Gulati et al., 2012). In understanding any system, the boundary issue is important. For biological ecosystem boundaries, both space and time are seen to play a crucial role (Post et al., 2007). This analogously applies to innovation ecosystems as well - even if they could be considered as open social systems (see Anderson, 1999; Scott and Davis, 2016), at least some semi-stable boundaries could be drawn. Typically, this involves identification of the focal firm, such as "Lego's ecosystem" (Hienerth et al., 2014), or discussion of the innovation or technology around which the system is formed (e.g., Battistella et al., 2013). 
Ecosystem boundaries could also be traced via geographical scope (local vs. regional or national vs. global); temporal scale (past to future or static snapshot vs. dynamic interaction); permeability (open vs. closed); or types of flow (knowledge, value, material) (Valkokari, 2015).

Finally, there is the pre-fix innovation, which can be defined as creation of new knowledge and inventions, and the successful commercial adoption of those to the markets (Crossan and Apaydin, 2010). Innovation ecosystems involve both of these aspects. In fact, Oh et al. (2016) also recognize that the tension between "research economy" and "commercial economy" might be behind the recent rise of the innovation ecosystem discussion. This is a good point, and also recently articulated by Clarysse et al. (2014), who found that the knowledge ecosystem (i.e., the research economy) and the business ecosystem (i.e., the commercial economy), are partially separate but intertwined within the broader context of innovation activities.

Inventions, ideas, and discoveries can be pursued by anyone, but the notion of successful commercialization hints strongly at the involvement of private sector actors. Unsurprisingly, then, innovation ecosystem has been adopted to describe profit-driven systems of innovation around focal companies, technologies and platforms (Li, 2009; Adner and Kapoor, 2010; Ritala et al., 2013; Overholm, 2015). However, there has also been a long standing tendency for public policy to support innovation initiatives in the name of economic development and societal progress. As Oh et al. (2016) note, this means that the concept of innovation ecosystem has begun to infiltrate spaces more traditionally described by such concepts as innovation system, triple-helix, or cluster. This has led to ambiguous usage and application of the concept. Thus, we call for a more mindful use of the terms eco and systems, as well as knowledge creation and market adoption aspects of innovation activities. This requires both rigorous scholarly work and careful usage of the concept.

\section{Toward greater rigor in innovation ecosystem research}

One critique of the concept of innovation ecosystem is that the deliberately designed ecosystems in business and innovation do not actually resemble natural ecosystems (Oh et al., 2016). The content and scope of the ecosystem concept is also debated in natural ecology (see O'Neill, 2001), increasing the likelihood of unproductive cross-disciplinary borrowing unless the conceptual underpinnings are clearly understood. On the other hand, technology and management literature involves also other powerful ecological analogies, shaping our 
understanding of the underlying phenomena. These include evolutionary economics (Nelson and Winter, 1982) and its subsequent iterations (e.g., Teece et al., 1997), with broadly adopted concepts of evolution and adaptation. Other evolutionary concepts such as technological speciation (Adner and Levinthal, 2002) and exaptation (Andriani and Cattani, 2016) also abound. Another ecological analogy widely used in management and innovation studies is "ambidexterity." Originally referring to the ability to use right and left hands equally well (Oxford Dictionaries, 2016), the concept is used in innovation and management studies to refer to capability for simultaneous exploration and exploitation (O'Reilly and Tushman, 2013). Biologically, two hands look very much alike; in an organizational context, exploration and exploitation certainly don't. This example shows that borrowing from biology need not always fully replicate the original term to be useful for scholarly purposes in another domain.

Nevertheless, even with plausible analogy, its application may be less satisfactory. Oh et al. (2016) find a lack of consistency in the use of the concept of innovation ecosystems to describe firm-led ecosystems, digital platforms, regional innovation ecosystems, university-led ecosystems, and so on. While it is true that the concept of ecosystem is in many cases used very loosely, a birds-eye view suggests that these approaches share several common features. First, innovation is a goal or focus of the ecosystem in all cases; it is the actors, contexts, and boundaries that change. Second, they typically entail one or several focal entities that are central to the ecosystem and help to define its boundaries - for instance, a particular firm ( $\mathrm{Li}$, 2009; Hienert et al., 2014), technology (Overholm, 2015), or digital platform (Cusumano and Gawer, 2002). So, although they are open social systems, it seems that innovation ecosystems are deliberately designed and evolve around key set of entities, at least at a particular point in time.

If conceptual clarity poses a challenge for innovation ecosystem scholarship, empirical inquiry may present an even larger obstacle, and it is no surprise that much of this research consists of case studies. However, even if qualitative case inquiries are likely to be appropriate for the study of such complex entities, the demands for embracing the concept in full are arguably near to insurmountable. In fact, Oh et al (2016) argue that sound measurement of progress of coevolution in innovation ecosystem is beyond current scientific capabilities. Given the multiple interdependencies between organizations, technologies, individuals and institutions, we agree that this seems a fair assessment. However, the same problem plagues studies on any multiactor networks. Thus, even granted the impossibility of a perfect research design, we believe it 
is worthwhile to engage in various forms of academic inquiry over the important real-life phenomena.

With the help of simulation modeling and related theories (e.g., systems theory, control theory), innovation ecosystem studies can evolve from being merely descriptive to become more predictive. Simulation studies (e.g., system dynamics, agent-based modeling) can also more successfully comprehend the complexity and dynamicity of innovation ecosystems. In general, simulation is useful for theory development, as it can expose the complex connections among constructs or the results of interactions among numerous organizational and strategic processes, especially as they unfold over time (Repenning, 2002; Zott, 2003; Davis et al., 2007). In addition, we also see the value of qualitative process research for the study of dynamic phenomena like innovation ecosystems as it can provide rich understanding on the hows and whys of these processes (Langley, 1999).

\section{The way forward: Some solutions and open questions}

In this short letter, we have addressed the burgeoning interest in the topic of innovation ecosystems and the related conceptual ambiguity challenges. We do not believe that our arguments are definitive or one-size-fits-all. Hoverer, we hope to spark active discussion and stimulate future work with improved conceptual and empirical rigor. To conclude, we summarize our arguments by responding to the four innovation ecosystem research challenges identified by Oh et al. (2016, p. 5).

\section{Whether and how innovation ecosystems differ from national and regional innovation} systems. Oh et al. (2016) argue convincingly that the established innovation systems literature already include the necessary ingredients for discussing national and regional innovation systems. They also list potentially differentiating features of recent innovation ecosystem studies. Among these, the "market-driven ecosystem movement" - may represent one key to unlock this conceptual ambiguity. In his early scholarly introduction of the business ecosystem concept, Moore (1993) was already pointing to the importance of an ecosystem perspective on innovation. In addition, other much cited sources of innovation ecosystems (e.g., Adner \& Kapoor, 2010), treated the concept very much as a market-driven phenomenon and did not consider policy issues in the same way as the innovation systems literature. 
This discussion brings us back to considering the role of public initiatives and of private business at large. At best, market-driven innovation ecosystems do what the profit-seeking corporations do best in any case: innovate, compete, create customer value, and subsequent economic progress. At the same time, publicly funded regional innovation systems and triplehelix initiatives should not be overlooked. Whatever the terms used to describe these phenomena, we believe that both are needed to facilitate innovation activities regionally, nationally, and globally. While only time will determine the traction of these concepts in different applications, perhaps the best solution is to scope innovation ecosystems in more market-driven initiatives while using other more established concepts to discuss public policy. There is certainly shades of grey between the contexts, which calls for even more care in choosing the proper concepts.

Measurement of innovation ecosystem performance. In the innovation management literature, there are several more or less established ways of measuring performance, including objective and subjective ways to measure outputs and processes. Some of these approaches could be viewed from ecosystem actor perspective and aggregated to system or sub-system levels. In reality, however, performance measurement of any collective multi-actor phenomenon is a difficult task; tensions and contradictions between actor- and system-specific goals are likely to emerge, raising questions about whose performance (and what) should be measured. Measurement could also remain completely external to the system, assessing the relative competitiveness of the ecosystem against competing innovations and technologies. In any case, as in any other study, performance metrics should be linked to the level of analysis and the research question.

Similarities and differences between natural and innovation ecosystems. While the similarities of natural and innovation ecosystems may prove useful for extending scholarship (as in the case of ambidexterity), any differences may prove dysfunctional unless properly acknowledged. As Oh et al. (2016, p. 2) observe, “An innovation ecosystem is not an evolved entity. Rather, it is designed." However, as previously noted by Nelson and Winter (1982), all organizations and technologies evolve over time, and the closer you look, the more evolution you find. That being so, the unique features of purposeful design and evolutionary nature may make the innovation ecosystem concept viable for examining real-world phenomena in both of these important respects. For that reason, it is important for ecosystem scholars to understand 
which parts of the ecosystem are (and can be) engineered, and which parts are self-organized or co-evolved.

Oh et al. (2016) highlight the difference in scope of natural and innovation ecosystems-that is, while natural ecosystems are local, innovation ecosystems can be global. However, in the biology literature that scope is not strictly defined either, as "an ecosystem may range from anthill to the entire biosphere of the globe" (Willis, 1997, p.). In fact, Willis argued that the concept's robustness is evident in its capacity for extension across scales, as well as its accommodation of both holistic and reductionist approaches. These benefits could equally apply to management and innovation studies. At the same time, this scalability of the concept makes its application problematic, as any networked innovation activity could be labeled an "ecosystem." In this regard, we call for critical thinking, focusing on the added value of the concept and all of its components.

To enhance the concept's applicability, we agree with Oh et al. (2016) that "innovation ecosystem theorists may relax some axioms of ecology (and perhaps introduce a small number of additional ones) in order to fit the needs of artificial "ecosystems." The development of such axioms is of fundamental importance to scholarship in the field. We believe that by utilizing some of the useful features of ecological thinking (e.g., co-evolution) and systems thinking (particularly complex adaptive systems), innovation ecosystem studies can embrace their research objects more holistically as well as more realistically.

Distinguishing the levels at which the term is used. As we iterated earlier, innovation ecosystem studies often seem to focus on dominant entities that determine their boundaries, such as hub firms, technologies, and platforms (e.g. Autio and Thomas, 2014). However, while the focal point of boundary definition may be a particular entity or platform, the level of the analysis can refer to the system itself. The challenges of such system-level analysis are many, and could be partially addressed by the use of different methodologies and making clear choices over level and unit of analysis. In this regard, we suggest that the term innovation ecosystem should ideally be used in respect of systems that focus on innovation activities (goal/purpose), involve the logic of actor interdependence within a particular context (spatial dimension) and address the inherent co-evolution of actors (temporal dimension). 


\section{References}

Adner, R. \& Kapoor, R. (2010). Value creation in innovation ecosystems: How the structure of technological interdependence affects firm performance in new technology generations. Strategic Management Journal, 31(3), 306-333.

Adner, R. \& Levinthal, D. A. (2002). The emergence of emerging technologies. California Management Review, 45(1), 50-66.

Anderson, P. (1999). Complexity Theory and Organization Science. Organization Science, 10(3), 216-232.

Andriani, P., \& Cattani, G. (2016). Exaptation as source of creativity, innovation, and diversity: Introduction to the special section. Industrial and Corporate Change, 25(1), 115-131.

Autio, E. \& Thomas, L. (2014). Innovation ecosystems. The Oxford handbook of innovation management, 204-288.

Battistella, C., Colucci, K., De Toni, A.F. \& Nonino, F. (2013). Methodology of business ecosystems network analysis: A case study in Telecom Italia Future Centre. Technological Forecasting \& Social Change, 80, 1194-1210.

Cilliers, P. (2005). The architecture of complexity (introduction). Emergence: Complexity and Organization, 7(3-4), 138-154.

Clarysse, B., Wright, M., Bruneel, J., \& Mahajan, A. (2014). Creating value in ecosystems: Crossing the chasm between knowledge and business ecosystems. Research Policy, 43(7), 1164-1176.

Crossan, M. M. \& Apaydin, M. (2010). A multi-dimensional framework of organizational innovation: A systematic review of the literature. Journal of Management Studies, 47(6), 11541191.

Cusumano, M. A. \& Gawer, A. (2002). The elements of platform leadership. MIT Sloan management review, 43(3), 51.

Davis, J.P., Eisenhardt, K.M. \& Bingham, C.B. (2007). Developing theory through simulation methods. Academy of Management Review, 32, 480-499.

Durst, S. \& Poutanen, P. (2013). Success factors of innovation ecosystems - Initial insights from a literature review. In R. Smeds \& O. Irrmann (eds.) CO-CREATE 2013: The BoundaryCrossing Conference on Co- Design in Innovation (pp. 27-38). Aalto University Publication series SCIENCE + TECHNOLOGY 15/2013.

Gulati, R., Puranam, P. \& Tushman, M. L. (2012). Meta-Organization Design: Rethinking Design in Interorganizational and Community Contexts. Strategic Management Journal, 33(6), 571-586.

Hienerth, C., Lettl, C. \& Keinz, P. (2014). Synergies among Producer Firms, Lead Users, and User Communities: The Case of the LEGO Producer-User Ecosystem. Journal of Product Innovation Management, 31(4), 848-866. 
Langley, A. (1999). Strategies for theorizing from process data. Academy of Management Review, 24(4), 691-710.

Li, Y. R. (2009). The technological roadmap of Cisco's business ecosystem. Technovation, 29(5), 379-386.

Moore, J. F. (1993). Predators and prey: a new ecology of competition. Harvard Business Review, 71(3), 75-86.

Nelson, R. \& Winter, S. (1982). An Evolutionary Theory of Economic Change. Harvard University Press, Cambridge, MA.

Oh, D. S., Phillips, F., Park, S., \& Lee, E. (2016). Innovation ecosystems: A critical examination. Technovation, 54, 1-6.

O'Neill, R. V. (2001). Is it time to bury the ecosystem concept? (With full military honors, of course!) Ecology, 82(12), 3275-3284.

O'Reilly, C. A. \& Tushman, M. L. (2013). Organizational ambidexterity: Past, present, and future. The Academy of Management Perspectives, 27(4), 324-338.

Oxford Dictionaries. (2016). Definition of ambidextrous in English. Retrieved from: https://www.oxforddictionaries.com/definition/english/ambidextrous?q=Ambidexterity\#ambi dextrous_5/

Overholm, H. (2015). Collectively created opportunities in emerging ecosystems: The case of solar service ventures. Technovation, 39, 14-25.

Peltoniemi, M. (2006). Preliminary theoretical framework for the study of business ecosystems. Emergence: Complexity and Organization, 8(1), 10-19.

Post, D., Doyle, M., Sabo, J. \& Finlay, J. (2007). The Problem of Boundaries in Defining Ecosystems: A Potential Landmine for Uniting Geomorphology and Ecology. Geomorphology, 89 (102): 111-126.

Repenning, N.P. (2002). A simulation-based approach to understanding the dynamics of innovation implementation. Organization Science, 13, 109-127.

Ritala, P., Agouridas, V., Assimakopoulos, D., \& Gies, O. (2013). Value creation and capture mechanisms in innovation ecosystems: a comparative case study. International Journal of Technology Management, 63(3-4): 244-267.

Scott, W. R., \& Davis, G. F. (2016). Organizations and organizing: Rational, natural and open systems perspectives. Routledge: New York.

Teece, D. J., Pisano, G., \& Shuen, A. (1997). Dynamic capabilities and strategic management. Strategic Management Journal, 18(7), 509-533.

Valkokari, K. (2015). Business, innovation, and knowledge ecosystems: How they differ and how to survive and thrive within them. Technology Innovation Management Review, 5, 17-24. von Bertalanffy, L. (1956). General Systems Theory. General Systems, 1, 1-10. 
Willis, A. J. (1997). Forum. The ecosystem: an evolving concept viewed historically. Functional Ecology, 11(2), 268-271.

Zott, C., (2003). Dynamic capabilities and the emergence of intraindustry differential firm performance: insights from a simulation study. Strategic Management Journal, 24, 97-125. 